\title{
Intimate partner violence during COVID-19 lockdown in Norway: the increase of police reports
}

Merete Berg Nesset ${ }^{1 *}$, Camilla Buch Gudde ${ }^{1}$, Gro Elisabet Mentzoni ${ }^{2}$ and Tom Palmstierna ${ }^{1,3}$

\begin{abstract}
Background: In March 2020, the Norwegian government announced a COVID-19 lockdown in order to reduce the spread of the coronavirus. In Norway, lockdown measures included restricting people's ability to leave their home and the closing of social institutions, thus reducing the capacity for victims of intimate partner violence to alert someone outside of their home about violent incidents that occurred during lockdown. At the same time, the restrictive measures forced the victim and the perpetrator to stay together for prolonged periods within the home, and reduced the possibility for them to escape or leave the perpetrator. The aim of this study was to investigate how the frequency and character of intimate partner violence reported to the police changed during the period of lockdown in Norway.
\end{abstract}

Methods: All cases of intimate partner violence registered in police files before the pandemic (from January 2016-February 2020) and during lockdown in Norway (March-December 2020) were included in the study, representing a total of 974 cases. Differences in the number and severity of cases were calculated using X2-tests and Wilcoxon's rank sum test. Differences in the characteristics of the reported violence was assessed with the Brief Spousal Assault form for the Evaluation of Risk (B-SAFER) and tested with Fischer's exact test with Bonferroni correction. Standardised Morbidity Rate (SMR) statistics were used to analyse the proportion of immigrants as compared to the general population.

Results: Reported intimate partner violence increased by $54 \%$ during the lockdown period in Norway. Between March-December 2020, the police assessed the cases as being at higher risk of imminent and severe violence. Our findings indicated an overrepresentation of immigrant perpetrators before and during lockdown (SMR $=1.814,95 \%$ $\mathrm{Cl}=1.792-1.836$ before, and $\mathrm{SMR}=1.807,95 \% \mathrm{Cl}=1.742-1.872$ during lockdown). Notably, while victims with an immigrant background were overrepresented before lockdown, we found significantly lower proportion of immigrant IPV victims during the lockdown period $(\mathrm{SMR}=1.070,95 \% \mathrm{Cl}=1.052-1.087$ before, and $\mathrm{SMR}=0.835, \mathrm{Cl} 95 \%$ $\mathrm{Cl}=0.787-0.883$ during lockdown). Also, there were significantly more female perpetrators and male victims reported to the police during the lockdown period. A higher proportion of the victims were assessed as having unsafe living conditions and personal problems during lockdown. Finally, during the lockdown period in Norway, a higher proportion of perpetrators had a history of intimate relationship problems.

\footnotetext{
*Correspondence: Merete.Berg.Nesset@stolav.no

1 Forensic Department and Research Centre Brøset, St. Olav's Hospital,

Trondheim University Hospital, PO 1803 Lade, N-7440, Trondheim,

Norway

Full list of author information is available at the end of the article
}

(C) The Author(s) 2021. Open Access This article is licensed under a Creative Commons Attribution 4.0 International License, which permits use, sharing, adaptation, distribution and reproduction in any medium or format, as long as you give appropriate credit to the original author(s) and the source, provide a link to the Creative Commons licence, and indicate if changes were made. The images or other third party material in this article are included in the article's Creative Commons licence, unless indicated otherwise in a credit line to the material. If material is not included in the article's Creative Commons licence and your intended use is not permitted by statutory regulation or exceeds the permitted use, you will need to obtain permission directly from the copyright holder. To view a copy of this licence, visit http://creativecommons.org/licenses/by/4.0/. The Creative Commons Public Domain Dedication waiver (http://creativeco mmons.org/publicdomain/zero/1.0/) applies to the data made available in this article, unless otherwise stated in a credit line to the data. 
Conclusions: Intimate partner violence increased dramatically during the COVID-19 lockdown. A range of options for victims to escape from their perpetrators, particularly during times of crisis, should be developed in line with good practice, and with a special focus on the most vulnerable victims.

Keywords: COVID-19, corona virus, lockdown, intimate partner violence, domestic violence, public health, prospective cohort study, violence risk assessment

\section{Background}

Intimate partner violence (IPV) was a worldwide health problem even before the COVID-19 pandemic, with a lifetime occurrence of physical and/or sexual violence by an intimate partner estimated to be $30 \%$ for women globally [1]. Intimate partner violence and violence against children have been described as a 'hidden pandemic' within the COVID-19 pandemic [2]. Furthermore, research has shown that during other crisis situations intimate partner violence has also increased, for example, during natural disasters [3]. The COVID-19 pandemic has led to rapid changes in peoples' daily routines, stayhome policies and lockdown of social institutions, such as schools and health centres. Furthermore, reduced capacity and more remote access to public institutions, including the police, health- and social services has led to a general concern about the situation for victims of intimate partner violence during the pandemic [4-7].

Although there is little scientific knowledge about the consequences of the COVID-19 pandemic on family violence, there are indications that social distancing and lockdowns of societies have increased family conflicts $[8,9]$. A recent systematic review and meta-analysis of 18 studies from countries around the world excluding Norway, found that intimate partner violence had increased after COVID-19 lockdowns (mean effect size $0.66, \mathrm{CI}=0.08-1.24$ ) [8]. Furthermore, the pandemic has caused increased stress within the home, such as increased poverty due to loss of employment, which in turn has been found to be associated with intimate partner violence [10]. Other known risk factors for intimate partner violence include lack of formal and informal support from health- and social services, friends and family, mental health problems and drug use [11, 12]. Accordingly, when social welfare institutions lock down, it is particularly important for police and health care services to be aware of, and available to victims of violence in a crisis like the COVID-19 pandemic.

Intimate partner violence includes physical violence, sexual violence, stalking and psychological aggression [13]. Exposure to violence from an intimate partner has been shown to have a long-term negative impact on the victims' psychological and physical well-being [14-16], and to represent significant economic costs to society $[17,18]$. Both men and women can be either perpetrators or victims of intimate partner violence, or they can be both. Previous research on intimate partner homicide has indicated that mutual violence between partners was common among cases that ended with homicide, with female partners being the victim of homicide in the majority of cases [19]. A meta-analysis examining the association between depression, anxiety, post-traumatic stress disorder (PTSD), antisocial personality disorder, borderline personality disorder, and physical intimate partner violence perpetration and victimisation among men and women, found a strong link between all of the studied mental health disorders and violence perpetration and victimisation for men and women [11].

Identifying intimate partner violence requires robust assessment procedures within police, health- and social services. The assessment of risk for intimate partner violence may be defined as the process of gathering information about people to make decisions regarding their risk of perpetrating intimate partner violence [20]. The aim of risk assessments for violence is to provide a sound basis for implementing effective protective measures and management plans to hinder future incidences of violence [21]. The Brief Spousal Assault Form for the Evaluation of Risk (B-SAFER) is such a structured professional judgement device designed for use in police and other criminal justice settings [22].

Importantly, police officers are often the first line responders to intimate partner violence, and evidence suggests that women exposed to potentially lethal violence are more likely to seek help from the police or health services [19]. Although previous research has examined characteristics of intimate partner violence, there is a need for much more research on the consequences of national lockdowns due to the COVID-19 pandemic in the number and severity of intimate partner violence cases. In addition, little is known about specific risk and vulnerability factors among perpetrators and victims associated with the pandemic lockdown situation, as assessed by the police. Furthermore, the knowledge about how the pandemic has influenced immigrants as victims and perpetrators of intimate partner violence is still limited.

The aim of this study was to investigate changes in character and occurrence of intimate partner violence (IPV) reported to the police during lockdown as compared 
to IPV incidents reported prior to the COVID-19 lockdown in Norway. Our pre-defined primary outcome was the number and severity of IPV cases before and during lockdown. The pre-defined secondary outcomes were differences in the characteristics of specific risk and vulnerability factors, and immigration status among perpetrators and victims before and during lockdown.

\section{Methods}

Design

All the data collected in this study relied upon all police reports within a defined area, Trøndelag County, Norway, including structured risk assessments conducted by specially assigned police officers. To meet the aim of the study, we compared characteristics of cases reported before the COVID-19 related lockdown in Norway in March 2020 with the same characteristics during March to December 2020. The current study is part of a prospective cohort file study of police risk assessments of all reported intimate partner violence cases in Trøndelag County, Norway since 2015. In this paper, we report findings from the full years of 2016-2020.

\section{Setting and Sample}

On a national level, the Norwegian police force has assigned police officers working with violence in the family. These police officers are responsible for performing risk assessments and suggesting interventions, using the B-SAFER risk assessment tool to guide decisions in this process. The structured professional judgement approach encourages professionals to use their own experience when working with intimate partner violence, combined with a focus on empirically supported risk factors when assessing risk for violence and deciding on relevant interventions [20, 22].

Our study was carried out within Trøndelag Police District in Norway. Population data for the Trøndelag region was retrieved from Statistisk Sentralbyrå (Statistics Norway, the official source of population data in Norway). Trøndelag County had a mean population during 20162020 of 461653 inhabitants. The mean proportion of immigrants was 10 per cent. During the period of $1^{\text {st }}$ January 2016 until $21^{\text {st }}$ December 2020, 974 IPV index cases with unique perpetrators were collected, representing all unique cases reported to the police during this period. Table 1 presents the sample characteristics.

\section{Material and procedure}

The police in Trøndelag Police Department performed B-SAFER assessments on all cases of IPV reported to the police. The data in the present study was collected and anonymized by one police employee. The anonymized ratings were collected by the researchers together with an
Table 1 Baseline characteristics for the sample. Values presented as mean and standard deviation (SD) or proportion (\%)

\begin{tabular}{lll}
\hline & Victims $(\mathbf{N = 9 7 4 )}$ & Perpetrators $(\mathbf{N = 9 7 4 )}$ \\
\hline $\begin{array}{l}\text { Age, mean, (SD), range } \\
\text { Sex, N (\%) }\end{array}$ & $36.6(11.5) 17-81$ & $39.4(12.1) 18-85$ \\
$\quad$ Male & $57(5.9)$ & $951(93.9)$ \\
$\quad$ Female & $917(94.1)$ & $59(6.1)$ \\
Origin of birth, N (\%) & & \\
$\quad$ Born in Norway & $818(84.0)$ & $684(70.2)$ \\
$\quad$ Born outside Norway & $156(16.0)$ & $290(29.8)$ \\
\hline
\end{tabular}

excel-file containing sociodemographic variables, including status such as immigrant.

A Norwegian translation of the original Swedish version of the B-SAFER was used in the study [23]. As noted earlier, B-SAFER is a research-based risk assessment tool for assessing and managing the risk of future partner violence [22]. It is a 15 -item risk-assessment tool that integrates both static and dynamic factors in relation to an IPV perpetrator's risk for future violence towards an identified partner. The B-SAFER items are divided into three domains: (i) Perpetrator risk factors, (ii) the perpetrator's psychosocial adjustment, and (iii) victim vulnerability factors (see Table 2).

Each factor is assessed as either present, partly present, not present or as 'impossible to assess' due to lack of information. The risk factors are considered to assess both the current situation (i.e. the last four weeks) and the past (prior to the last four weeks).

Finally, all the information, together with the police's professional judgement, is summarized within two risk ratings: One for acute/imminent violence and one for severe/fatal violence. The estimated risk ratings are assessed on a three-level risk scale: Low, medium or high.

\section{Analyses/Statistics}

Analysis of the differences in the number of IPV-cases before and during COVID-19 related lockdown in Norway reported to the police were calculated with $\mathrm{X}^{2}$-analysis. Differences between the two periods regarding acute/imminent violence and severe/fatal violence were analysed with Wilcoxon rank sum test giving the score "1" for "Low risk", "2" for "Medium risk" and " 3 " for High risk".

Differences in perpetrator risk factors, psychosocial adjustment and victim vulnerability factors were compared across the two time periods. All items of the B-SAFER were used for this purpose, with the exception of the items relating to 'previous victim vulnerability' which we lacked information about during the first 
Table 2 The Brief Spousal Assault Form for the Evaluation of Risk (B-SAFER)

\begin{tabular}{lll}
\hline Perpetrator risk factors & Psychosocial adjustment & Victim vulnerability factors \\
\hline Violent acts & General criminality & Inconsistent behavior/attitude \\
Violent threats or thoughts & Intimate relationship problems & Extreme fear \\
Escalation & Employment problems & Inadequate access to resources \\
Violation of court orders & Substance use problems & Unsafe living situation \\
Violent attitudes & Mental health problems & Personal problems \\
\hline
\end{tabular}

years of the larger study. To exclude 'previous victim vulnerability' was in line with recommendations from a previous study carried out by Belfrage et al. in 2008 [24]. In accordance with our previous study on police officers use of the B-SAFER [25], item scores of 'present' or 'partly present' were judged as the risk factor being present. The scoring of "not present" was judged as the risk factor not being present. Using the B-SAFER in this way results in 25 items to analyse. The findings were calculated using Fischer's exact test when comparing proportion of present/non-present risk factors before and during lockdown. Due to the large number of tests in this analysis, Bonferroni correction was used for accepting a significance level of $5 \%$, i.e. only tests with $p<0.002$ were accepted as significant.

Over- or underrepresentation of immigrants as perpetrators and victims as compared to the general population in the Trøndelag County was calculated as the quotient between observed numbers of immigrants divided by the age and sex adjusted expected number of immigrants in line with Standardised Morbidity Rate (SMR) statistics. Expected numbers of immigrants was calculated yearly since the proportion of immigrants in the general population increased from 9.1-10.8\% between 2016 and 2020. Calculations were performed for the whole period, but also separately for the period before lockdown (January 2016-February 2020) and during lockdown (March 2020-December 2020).

\section{Results \\ Number and severity of IPV cases before and during lockdown}

We found a significant increase in intimate partner violence reported to the police during the lockdown period. In the study period before lockdown, i.e. between January 2016 and February 2020, 745 cases of IPV were reported, representing 14.9 cases per month (50 months in total). During the lockdown period studied, March-December 2020, 229 cases of IPV were reported, which constitutes 22.9 cases per month (10 months in total). This is an increase of $54 \%$ and statistically significant in $\chi^{2}$ testing with $\mathrm{X}^{2}=32.9, \mathrm{df}=1, p<0.00001$.
The police assessments of risk for acute/imminent violence was significantly higher during the lockdown period. There were 744 assessments (one missing) before lockdown that had a mean score of 1.59 and there were 229 assessments during lockdown that had a mean score of 1.67 . This difference is statistically significant at the $5 \%$ level with Wilcoxon rank sum test, $p=0.0499$.

Further, there was a trend towards a higher risk for severe reoffending among the cases during lockdown, although the difference was not statistically significant (Wilcoxon rank sum test, $p=0.054$ ); The 745 assessments before lockdown had a mean score of 1.49 and the 229 assessments during lockdown had a mean score of 1.57.

\section{Differences in perpetrator's risk factors and victim's vulnerability factors before and during lockdown}

As presented in Table 3 below, the perpetrator risk factors were virtually the same before and during lockdown. Current and past violent acts were very similar. What differed was that in the lockdown group, there was a higher frequency of intimate relationship problems in the past, a higher proportion of current unsafe living situation and a higher proportion of current personal problems.

\section{Immigrants and differences in being perpetrator and victim before and during lockdown}

During the overall study period of 2016-2020, 290 of the 974 perpetrators were immigrants which is a significant overrepresentation with $\mathrm{SMR}=1.812,95 \% \mathrm{CI}=1.796-$ 1.828. Also, 156 of the 974 victims were immigrants, which was a small but significant overrepresentation with $\mathrm{SMR}=1.013,95 \% \mathrm{CI}=1.0003-1.026$.

The overrepresentation of immigrants among the perpetrators was about the same before lockdown (January 2016-February 2020) as during lockdown (March-December 2020). 217 of the 745 perpetrators before lockdown, and 73 of the 229 perpetrators during lockdown were immigrants, representing an overrepresentation in both groups with $\mathrm{SMR}=1.814$, 95\% $\mathrm{CI}=1.792-1.836$ before, and $\mathrm{SMR}=1.807,95 \%$ $\mathrm{CI}=1.742-1.872$ during lockdown.

The overrepresentation of immigrants among victims changed during lockdown. Before lockdown, 125 of the 
Table 3 B-SAFER risk and vulnerability factors before and during the COVID-19 lockdown

\begin{tabular}{|c|c|c|c|c|c|c|c|}
\hline \multirow[t]{2}{*}{ B-SAFER item } & \multicolumn{3}{|c|}{$\begin{array}{l}\text { Before lockdown (Jan 2016-February } \\
\text { 2020) }\end{array}$} & \multicolumn{3}{|c|}{$\begin{array}{l}\text { During lockdown (March-December } \\
\text { 2020) }\end{array}$} & \multirow[b]{2}{*}{$P^{b}$} \\
\hline & Present & $\begin{array}{l}\text { Total } \mathrm{N} \text { of } \\
\text { responses }\end{array}$ & $\%$ & Present & $\begin{array}{l}\text { Total } \mathrm{N} \text { of } \\
\text { responses }\end{array}$ & $\%$ & \\
\hline \multicolumn{8}{|l|}{ Perpetrator risk factors } \\
\hline Violent acts, current & 550 & 725 & 76 & 169 & 222 & 76 & 1.000 \\
\hline Violent acts, in the past & 537 & 701 & 77 & 168 & 207 & 81 & 0.184 \\
\hline Violent threats or thoughts, current & 294 & 697 & 42 & 91 & 190 & 48 & 0.563 \\
\hline Violent threats or thoughts, in the past & 311 & 616 & 50 & 72 & 175 & 41 & 0.032 \\
\hline Escalation, current & 315 & 673 & 47 & 113 & 197 & 57 & 0.010 \\
\hline Escalation, in the past & 250 & 634 & 39 & 94 & 183 & 51 & 0.005 \\
\hline Violation of court orders, current & 58 & 726 & 8 & 18 & 226 & 8 & 1.000 \\
\hline Violation of court orders, in the past & 51 & 723 & 7 & 10 & 225 & 4 & 0.212 \\
\hline Violent attitudes, current & 396 & 578 & 69 & 107 & 165 & 65 & 0.396 \\
\hline Violent attitudes, in the past & 276 & 497 & 56 & 68 & 132 & 52 & 0.432 \\
\hline \multicolumn{8}{|l|}{ Psychosocial adjustment } \\
\hline General criminality, current & 215 & 724 & 30 & 80 & 226 & 35 & 0.118 \\
\hline General criminality, in the past & 467 & 721 & 65 & 153 & 223 & 69 & 0.333 \\
\hline Intimate relationship problems, current & 450 & 619 & 73 & 152 & 184 & 83 & 0.007 \\
\hline Intimate relationship problems, in the past ${ }^{\mathrm{a}}$ & 356 & 570 & 62 & 140 & 175 & 80 & 0.000 \\
\hline Employment problems, current & 261 & 602 & 43 & 90 & 182 & 49 & 0.149 \\
\hline Employment problems, in the past & 205 & 549 & 37 & 74 & 171 & 43 & 0.178 \\
\hline Substance use problems, current & 308 & 582 & 53 & 112 & 185 & 61 & 0.075 \\
\hline Substance use problems, in the past & 328 & 584 & 56 & 120 & 187 & 64 & 0.610 \\
\hline Mental health problems, current & 238 & 409 & 58 & 88 & 130 & 68 & 0.640 \\
\hline Mental health problems, in the past & 212 & 381 & 56 & 85 & 130 & 65 & 0.064 \\
\hline \multicolumn{8}{|l|}{ Victim vulnerability factors } \\
\hline Inconsistent behavior/ attitude, current & 383 & 701 & 55 & 129 & 211 & 61 & 0.097 \\
\hline Extreme fear, current & 251 & 642 & 39 & 91 & 196 & 46 & 0.690 \\
\hline Inadequate access to resources, current & 188 & 615 & 31 & 69 & 191 & 36 & 0.156 \\
\hline Unsafe living situation, current ${ }^{\mathrm{a}}$ & 384 & 649 & 59 & 161 & 220 & 73 & 0.000 \\
\hline Personal problems, current ${ }^{a}$ & 332 & 603 & 55 & 139 & 204 & 68 & 0.001 \\
\hline
\end{tabular}

${ }^{a}$ Significant with $a<5 \%$ with Bonferroni correction

${ }^{\mathrm{b}}$ Two-sided Fischer's exact test

745 victims were immigrants which was an overrepresentation with a $\mathrm{SMR}=1.070,95 \% \mathrm{CI}=1.052-1.087$. On the contrary, during lockdown, only 31 of the 229 victims were immigrants, $\mathrm{SMR}=0.835,95 \% \mathrm{CI}=0.787-0.883$ which was a significant underrepresentation of victims born outside of Norway.

\section{Age and gender of perpetrators and victims before and during lockdown}

There were no differences in age before and during lockdown for neither perpetrators nor victims (Student's t-test). The 745 perpetrators registered before lockdown had a mean age of 39.5, S.D. 12.0, range 18-83. The 229 perpetrators registered during lockdown had a mean age of 38.9 , S.D. 12.5 , range 19-85.
The 745 victims registered before lockdown had a mean age of 36.4, S.D. 11.2, range $17-81$. The 229 victims registered during lockdown had a mean age of 37.0, S.D. 12.5 , range $18-76$.

During lockdown there was a substantially higher proportion of female perpetrators. A total of 25 of the $229(10.9 \%)$ perpetrators were women, as compared to the pre-lockdown period where 34 of the $745(4.6 \%)$ perpetrators were women (Fischer's exact test doublesided, $p=0.00124$ ).

During lockdown, there was a substantially higher proportion of male victims. A total of 23 of the 229 (10.0\%) victims were men, as compared to the pre-lockdown period where 34 of the $745(4.6 \%)$ of the victims were men (Fischer's exact test double-sided, $p=0.00344$ ). 


\section{Discussion}

\section{Summary}

In line with the growing literature assessing the link between the COVID-19 pandemic and IPV [5, 6, 8, 9], intimate partner violence in Norway, as reported to the police, increased substantially during lockdown compared to the pre-lockdown period. Similar results has been found in previous studies on intimate partner violence during the COVID-19 pandemic [9]. Furthermore, during lockdown the police assessed the cases as being at higher risk for imminent and severe violence. Notably, our findings indicated an over-representation among immigrant perpetrators, both before and during lockdown. While victims with immigrant backgrounds were over-represented in the pre-lockdown period, we found a significantly higher proportion of native Norwegian IPV victims during the lockdown period. Moreover, during lockdown, there were significantly more reports made to the police about intimate relationship problems, as well as female perpetrators and male victims.

\section{Comparisons with existing literature}

As Norwegian health and social institutions locked down, and the availability of informal networks was reduced in 2020, the police service was one of a few institutions that remained open to the public. Our study found that during the lockdown period in Norway, police officers assessed an increased risk of violence in the near future among IPV victims, which may indicate a higher awareness among police officers about the potentially increased risk of family violence created by COVID-19 restrictions. Other studies have reported less access to medical services, as well as more severe injuries among IPV victims during COVID-19 lockdowns [26, 27]. Even though the finding in our study that the risk for severe violence was higher during lockdown did not reach statistical significance, it is still a relevant finding in a public health perspective $[5,6]$. When the government initiated stay-at-home orders to avoid the spread of the COVID19 virus, those individuals, already vulnerable to intimate partner violence, became trapped together with their perpetrator $[7,9]$. As such, in the aftermath of this global crisis, health and social institutions may have to address the consequences of a pandemic of family violence.

According to the B-SAFER assessment tool, most cases in the study had a history of intimate partner violence, both pre-lockdown and during lockdown, which is in line with research showing that women who were already victims of intimate partner violence reported higher frequencies of violence than those who had not experienced violence before the lockdown [9]. In addition, the fact that in most cases the violence was recurrent indicates that those individuals who were already among the most vulnerable in society faced an even more difficult time during lockdown. Research on intimate partner violence has highlighted that violence within the family is associated with mental health problems, as well as drug use and economic difficulties $[11,12]$. In this study, we found that most of the B-SAFER risk and vulnerability factors did not differ before and during the lockdown. However importantly, during lockdown significantly more victims were assessed as having personal problems and unsafe living conditions. In line with these findings, during lockdown the police in our study assessed a higher risk for IPV in the near future. The lockdown limited individuals' ability to move outside of their home, which may have resulted in high psychological distress among the perpetrators and the victims. Hence, the victims were more vulnerable to incidents of violence during lockdown. This could perhaps also explain the increased proportion of female perpetrators during lockdown. Of significance, a cross-sectional study of self-reported violence in the early stages of the pandemic reported higher prevalence of male victims of intimate partner violence as compared to the general population [28]. Anxiety stemming from an insecure employment situation, staying home for long periods of time with children and partner, reduced possibilities to be with friends and wider family members, or colleagues at work, may all have impacted negatively on individuals' ability to cope with intimate partner conflicts.

Another interesting finding was the higher proportion of native Norwegian victims of IPV during lockdown, as compared to immigrant victims. Intimate partner violence disproportionately affects marginalized groups like immigrants. Hence, one would expect an increased proportion of victims with an immigrant background during lockdown. Even though our study cannot draw any conclusions, one may speculate that our findings are associated with increased isolation among the immigrant population, less opportunity for immigrant victims to find safe havens and restricted access to health and social institutions during lockdown, which has been reported in previous studies [7,9]. At the same time, native Norwegian victims, as opposed victims with immigrant background, may have more confidence that the police can help them, and were therefore more willing to contact the police.

\section{Strengths and limitations}

A strength of this study was that it included all cases reported to the police in a defined geographical region. Moreover, the study period of the lockdown was 10 months, which enabled the researchers to observe consequences over time. 
On the other hand, our study only included information about the cases reported to the police. Consequently, since we do not know if the propensity to report to the police has changed during lockdown, we cannot say anything about changes in actual numbers of intimate partner violence in the population during lockdown.

\section{Conclusions}

In this study we found a substantial increase in the number and severity of reported cases of intimate partner violence during lockdown in Norway. The results indicate a need to create a wide range of options for victims to leave their perpetrator, particularly during times of crisis, and with special focus on assisting the most vulnerable victims in society.

\section{Abbreviations}

B-SAFER: The Brief Spousal Assault Form for the Evaluation of Risk; Cl: Confidence Interval; DPIA: Data Protection Impact Assessment; GDPR: General Data Protection Regulation; IPV: Intimate Partner Violence; SD: Standard deviation; SMR: Standard Morbidity Rate.

\section{Acknowledgements}

The authors would like to thank St. Olav's University Hospital, forensic dept. Brøset in Trondheim, Norway and Trøndelag Police District, Norway, for supporting the research. We also are grateful to Alice Steinkellner, senior advisor at Statistics Norway for skillful and prompt delivery of relevant population data.

\begin{abstract}
Authors' contributions
MBN developed the study protocol, interpreted the data and was a major contributor in writing the manuscript. CBG developed the study protocol, collected and interpreted the data and was a major contributor in writing the manuscript. TP developed the study protocol, performed the statistical analyses and interpreted the data, and was a major contributor in writing the manuscript. GEM contributed in developing the study protocol and collected the data. All authors read and approved the final manuscript.
\end{abstract}

\section{Funding}

Forensic Department and Research Centre Brøset, St. Olav's Hospital, Trondheim University Hospital, Norway supported the study as employer for the corresponding author. The funding body had no role in the design of the study or the collection, analysis or interpretation of the data or in writing the manuscript.

\section{Availability of data and materials}

All data generated or analysed during this study were included in this published article.

\section{Declarations}

\section{Ethics approval and consent to participate}

Anonymized data were collected from police registries. The Regional Committee for Medical and Health Research Ethics in Central Norway concluded that the project was not covered by the objective scope of the Health Research Act and found that there was no need to approve this study before implementation and publishing (no. 2018/639). The need for consent was waived by the Office of the Public Prosecutor for Norway, the Norwegian Police Directorate and Norwegian Social Science Data services. The study met the requirements in accordance with the General Data Protection Regulation (GDPR) and a Data Protection Impact Assessment (DPIA) was conducted (no. 59923).

\section{Consent for publication}

Not applicable.

\section{Competing interests}

The authors declare that they have no competing interests.

\section{Author details}

${ }^{1}$ Forensic Department and Research Centre Brøset, St. Olav's Hospital, Trondheim University Hospital, PO 1803 Lade, N-7440, Trondheim, Norway. ${ }^{2}$ Trøndelag Police District, Crime Prevention Department, The Children's House, Trondheim, Norway. ${ }^{3}$ Faculty of Medicine and Health Sciences, Department of Mental Health, Norwegian University of Science and Technology (NTNU), Trondheim, Norway.

Received: 6 August 2021 Accepted: 9 December 2021

Published online: 16 December 2021

\section{References}

1. Stöckl H, Devries K, Rotstein A, Abrahams N, Campbell J, Watts C, et al. The global prevalence of intimate partner homicide: a systematic review. The Lancet. 2013:382(9895):859-65.

2. Evans ML, Lindauer M, Farrell ME. A pandemic within a pandemic - Intimate partner violence during Covid-19. N Engl J Med. 2020;383(24):2302-4

3. Parkinson D. Investigating the Increase in Domestic Violence Post Disaster: An Australian Case Study. J Interpers Violence. 2019;34(11):2333-62.

4. EIGE. The Covid-19 pandemic and intimate partner violence against women in the EU. Luxembourg: European Institute for Gender Equality; 2021.

5. Roesch E, Amin A, Gupta J, García-Moreno C. Violence against women during covid-19 pandemic restrictions. UK: British Medical Journal Publishing Group; 2020.

6. Campbell AM. Improving prevention of family violence during (and after) disaster: Lessons learned from the Covid-19 pandemic. Forensic Science International: Reports. 2021;3:100179.

7. Sabri B, Hartley M, Saha J, Murray S, Glass N, Campbell JC. Effect of COVID-19 pandemic on women's health and safety: A study of immigrant survivors of intimate partner violence. Health Care Women Int. 2020;41(11-12):1294-312.

8. Piquero AR, Jennings WG, Jemison E, Kaukinen C, Knaul FM. Domestic violence during the COVID-19 pandemic - Evidence from a systematic review and meta-analysis. Journal of Criminal Justice. 2021;74:101806.

9. Lausi G, Pizzo A, Cricenti C, Baldi M, Desiderio R, Giannini AM, et al. Intimate Partner Violence during the COVID-19 Pandemic: A Review of the Phenomenon from Victims' and Help Professionals'Perspectives. Int J Environ Res Public Health. 2021;18(12):6204.

10. Jewkes R. Intimate partner violence: causes and prevention. The lancet. 2002;359(9315):1423-9.

11. Spencer CM, Mallory AB, Cafferky BM, Kimmes JG, Beck AR, Stith SM Mental health factors and intimate partner violence perpetration and victimization: A meta-analysis. Psychol Violence. 2019;9(1):1.

12. Nesset MB, Bjørngaard JH, Whittington R, Palmstierna T. Does cognitive behavioural therapy or mindfulness-based therapy improve mental health and emotion regulation among men who perpetrate intimate partner violence? A randomised controlled trial. Int J Nurs Stud. 2021:113:103795

13. Smith SG, Basile KC, Gilbert LK, Merrick MT, Patel N, Walling M, et al. National intimate partner and sexual violence survey (NISVS): 2010-2012 state report. 2017

14. Breiding MJ. Prevalence and characteristics of sexual violence, stalking, and intimate partner violence victimization-National Intimate Partner and Sexual Violence Survey, United States, 2011. Morbidity and mortality weekly report Surveillance summaries (Washington, DC: 2002). 2014;63(8):1.

15. Capaldi DM, Knoble NB, Shortt JW, Kim HK. A systematic review of risk factors for intimate partner violence. Partn Abus. 2012;3(2):231-80.

16. Garcia-Moreno C, Jansen HA, Ellsberg M, Heise L, Watts CH. Prevalence of intimate partner violence: findings from the WHO multicountry study on women's health and domestic violence. The lancet. 2006;368(9543):1260-9. 
17. Peterson C, Kearns MC, McIntosh WL, Estefan LF, Nicolaidis C, McCollister $\mathrm{KE}$, et al. Lifetime economic burden of intimate partner violence among US adults. Am J Prev Med. 2018;55(4):433-44.

18. Rasmussen I, Strøm S, Sverdrup S, Vennemo H. Samfunnsøkonomiske kostnader av vold i nære relasjoner. 2012. Report No.: 2012/41.

19. Vatnar SKB, Friestad C, Bjørkly S. Intimate partner homicide in Norway 1990-2012: Identifying risk factors through structured risk assessment, court documents, and interviews with bereaved. Psychol Violence. 2017;7(3):395

20. Kropp PR, Hart SD. Manual for the spousal assault risk assessment guide_SARA-V3. 3rd ed: Proactive Resolutions; 2015.

21. Nicholls TL, Pritchard MM, Reeves KA, Hilterman E. Risk assessment in intimate partner violence: A systematic review of contemporary approaches. Partn Abus. 2013;4(1):76-168

22. Kropp PR, Hart SD, Belfrage H. Brief Spousal Assault Form for the Evaluation of Risk (B-SAFER): User manual. 2nd ed: ProActive ReSolutions; 2010

23. Nøttestad JA, Lynum C. Bedømming av risikoen for gjentatt partnervold(SARA: SV) Versjon 2. Brukermanual. (Norwegian version). Norway2011.

24. Belfrage H, Strand S. Structured spousal violence risk assessment: Combining risk factors and victim vulnerability factors. Int J Forensic Ment Health. 2008;7(1):39-46.

25. Nesset MB, Bjørngaard JH, Nøttestad JA, Whittington R, Lynum C, Palmstierna T. Factors associated with police decisions on immediate responses to intimate partner violence. J Interpers Violence. 2017;35(15-16):2993-3010.

26. Rhodes HX, Petersen K, Lunsford L, Biswas S. COVID-19 resilience for survival: occurrence of domestic violence during lockdown at a rural American college of surgeons verified level one trauma center. Cureus. 2020;12(8).

27. Gosangi B, Park H, Thomas R, Gujrathi R, Bay CP, Raja AS, et al. Exacerbation of physical intimate partner violence during COVID-19 pandemic. Radiology. 2021;298(1):E38-45.

28. Jetelina KK, Knell G, Molsberry RJ. Changes in intimate partner violence during the early stages of the COVID-19 pandemic in the USA. Inj Prev. 2021;27(1):93-7.

\section{Publisher's Note}

Springer Nature remains neutral with regard to jurisdictional claims in published maps and institutional affiliations.

Ready to submit your research? Choose BMC and benefit from:

- fast, convenient online submission

- thorough peer review by experienced researchers in your field

- rapid publication on acceptance

- support for research data, including large and complex data types

- gold Open Access which fosters wider collaboration and increased citations

- maximum visibility for your research: over $100 \mathrm{M}$ website views per year

At BMC, research is always in progress.

Learn more biomedcentral.com/submissions 